\title{
Simultaneous abdominal aorta balloon occlusion without radiation exposure during caesarean section in placenta percreta patients: an effective easy-to-implement procedure for hemorrhage control.
}

\author{
Guang Xin Yang ${ }^{1}$, Jing Yuan $\mathrm{LUAN}^{1}$, Yan WANG${ }^{1}$, and Yang Yu ZHAO${ }^{1}$ \\ ${ }^{1}$ Peking University Third Hospital
}

May 5, 2020

\begin{abstract}
Abstract Objective: To research the safety and effect of the simultaneous abdominal aorta balloon occlusion without radiation exposure during caesarean section in placenta percreta patients. Design: A retrospective case study. Setting: A class A tertiary comprehensive hospital in Beijing of China. Population or Sample: 28 pregnant women from September 1st, 2015, to January 31st, 2019 Methods: The medical records of 28 patients with placenta percreta, who undertook the simultaneous abdominal aortic balloon occlusion without radiation exposure during caesarean section, were retrospective studied. Main Outcome Measures: The intra-operative blood loss, transfusion requirements, hysterectomy rate, the duration of operation, length of Intensive Care Unit time and postoperative hospital stay. Results: The technical success rate was 100\%. The amount of blood loss was $600-6500(3094 \pm 1502)$ ml. The duration of operation was $123-488(285 \pm 102)$ min. The mean Intensive Care Unit time and postoperative hospital stay were 2.0 (1.0 - 2.8) days and 7.0 (7.0 - 9.0) days respectively. Hysterectomy was carried out in $12(42.9 \%)$ cases. No maternal and neonatal deaths. The complication included 7 cases of local thrombosis of right femoral artery. Thrombectomy was successfully performed through the femoral artery incision on the operating table simultaneously. There was no other complication. Conclusions: The simultaneous abdominal aorta balloon occlusion without radiation exposure during caesarean section in placenta percreta patients is a safe and effective procedure for hemorrhage control. It is an easy-to-implement procedure by a well-trained surgeon which performed in the general operation room.
\end{abstract}

\section{Hosted file}

Manuscript.docx available at https://authorea.com/users/300784/articles/430621-simultaneousabdominal-aorta-balloon-occlusion-without-radiation-exposure-during-caesarean-sectionin-placenta-percreta-patients-an-effective-easy-to-implement-procedure-for-hemorrhagecontrol 


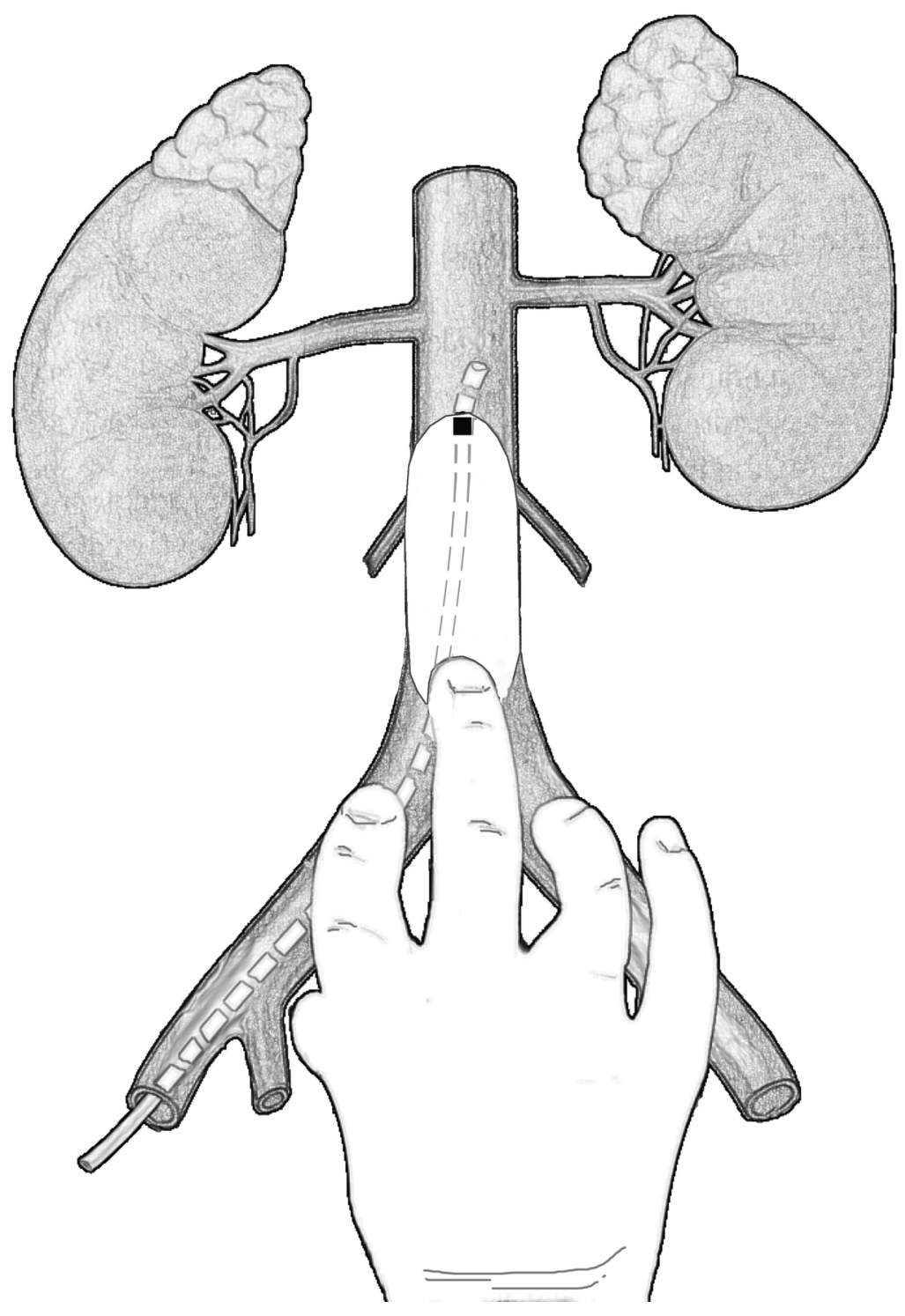

\section{Hosted file}

Table1.docx available at https://authorea.com/users/300784/articles/430621-simultaneousabdominal-aorta-balloon-occlusion-without-radiation-exposure-during-caesarean-sectionin-placenta-percreta-patients-an-effective-easy-to-implement-procedure-for-hemorrhagecontrol

\section{Hosted file}

Table2.docx available at https://authorea.com/users/300784/articles/430621-simultaneousabdominal-aorta-balloon-occlusion-without-radiation-exposure-during-caesarean-sectionin-placenta-percreta-patients-an-effective-easy-to-implement-procedure-for-hemorrhagecontrol

\section{Hosted file}


Table3.docx available at https://authorea.com/users/300784/articles/430621-simultaneousabdominal-aorta-balloon-occlusion-without-radiation-exposure-during-caesarean-sectionin-placenta-percreta-patients-an-effective-easy-to-implement-procedure-for-hemorrhagecontrol 